\title{
Nathalie Etoke, Black Blanc Beur: ma France à moi
}

\section{Ilaria Vitali}

\section{(2) OpenEdition}

\section{Journals}

\section{Edizione digitale}

URL: http://journals.openedition.org/studifrancesi/7054

DOI: 10.4000/studifrancesi.7054

ISSN: 2427-5856

\section{Editore}

Rosenberg \& Sellier

\section{Edizione cartacea}

Data di pubblicazione: 1 septembre 2010

Paginazione: 415

ISSN: 0039-2944

\section{Notizia bibliografica digitale}

Ilaria Vitali, «Nathalie Etoke, Black Blanc Beur: ma France à moi», Studi Francesi [Online], 161 (LIV | II) |

2010, online dal 30 novembre 2015, consultato il 09 janvier 2021. URL: http://

journals.openedition.org/studifrancesi/7054 ; DOI: https://doi.org/10.4000/studifrancesi.7054

\section{Questo documento è stato generato automaticamente il 9 janvier 2021}

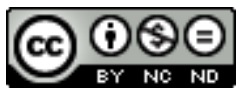

Studi Francesi è distribuita con Licenza Creative Commons Attribuzione - Non commerciale - Non opere derivate 4.0 Internazionale. 


\title{
Nathalie Etoke, Black Blanc Beur: ma France à moi
}

\author{
Ilaria Vitali
}

\section{NOTIZIA}

NATHALIE ETOKE, Black Blanc Beur: ma France à moi, «Nouvelles Études Francophones», vol. 24, n. 1, primavera 2009, pp. 157-171.

1 Il titolo di questo articolo di Nathalie Etoke conduce subito il lettore al cuore del tema analizzato: l'identità - problematica - della Francia contemporanea. Giocando sui colori della bandiera «bleu blanc rouge», la formula «black blanc beur», già usata negli anni 90 per indicare la multietnicità del paese, mira a suggerire una nuova identità nazionale, mostrando le molteplici componenti etniche e socioculturali dell'Hexagone. Partendo da riferimenti letterari, musicali e artistici, l'autrice affronta in questo studio il complesso tema dell'integrazione delle «seconde generazioni», spesso vittime di quel «retour du colonial» che negli ultimi tempi è sembrato riaffacciarsi con prepotenza sulla scena politica e culturale d'oltralpe. Come afferma Achille Mbembe, citato nell'articolo, «l'extension de la citoyenneté aux descendants d'esclaves n'a pas entraîné une transformation profonde de la manière dont nous procédons à la figuration politique de la démocratie» (L'impensé de la race, 2005, p. 149). Basandosi su molteplici riflessioni critiche e su diverse opere letterarie incentrate sul tema dell'identità nella Francia postcoloniale - interessante in particolare il riferimento al volume a cura di Blanchard, Bancel e Lemaire, La Fracture coloniale, 2005 -, lo studio mostra come diversi artisti contemporanei ne stiano tentando il rinnovamento. È il caso, tra gli altri, dell'autore di origine marocchina Mohamed Razane, fondatore del collettivo di scrittori di banlieue «Qui fait la France?» e autore di un romanzo esplosivo che narra la spietata quotidianità delle cités del nuovo millennio (Dit violent, 2006). Oltre alla letteratura, ampio spazio è dedicato da Etoke anche ad altre produzioni artistiche, come la musica della rapper di origine cipriota Diam's, autrice di una canzone dall'eloquente titolo «Ma France à moi», aspra critica dell'identité bleu-blanc-rouge. Un articolo interessante, che 
porta l'attenzione su un tema di grande attualità in un momento in cui il «grand débat sur l'identité nationale» (www.debatidentitenationale.fr/), aperto in Francia lo scorso novembre, continua a far discutere. 